\title{
The evaluation of psychological state of dental students during the COVID-19 pandemic
}

\author{
Tuba Talo YILDIRIM ${ }^{(a)}$ \\ Osman ATAS(b)
}

(a)Firat University, Faculty of Dentistry, Department of Periodontology, Elazig, Turkey.

(b)Firat University, Faculty of Dentistry, Department of Pediatric Dentistry, Elazig, Turkey.

Declaration of Interests: The authors certify that they have no commercial or associative interest that represents a conflict of interest in connection with the manuscript.

\section{Corresponding Author:}

Tuba Talo Yildirim

E-mail:dt_talo@hotmail.com

https://doi.org/10.1590/1807-3107bor-2021.vol35.0069

Submitted: May 20, 2020

Accepted for publication: July 27, 2020

Last revision: March 25, 2021

\begin{abstract}
The purpose of the present study was to assess anxiety among a sample of dentistry students during the COVID-19 pandemic. A total of 355 dentistry students (165 males and 190 females) completed the Health Anxiety Inventory (HAI), Beck Anxiety Inventory (BAI), State-Trait Anxiety Inventory-I (STAI-I), and State-Trait Anxiety Inventory II (STAI-II) questionnaires. and evaluations of HAI, BAI, STAI-I, and STAI-II were based on sex, dental school year, smoking habit, and lifestyle. Female students had higher HAI and BAI scores than male students ( $p=0.009$ and $p=0.001$, respectively). Statistically significant differences in HAI scores existed between preclinical and clinical students $(p=0.048)$. The only statistical significant differences detected in STAI-I scores involved students with an extended family when compared to students without an extended family $(\mathrm{p}=0.039)$. The HAI scores of students who had close contact were significantly higher than students who had no contact $(p=0.047)$. There were significant correlations between the four scales $(p<0.05)$. During the COVID-19 pandemic [was under control in Turkey?], the HAI scores were higher in female, clinical students and students who lived with an extended family.
\end{abstract}

Keywords: COVID-19; Students, Dental; Psychology; Fear.

\section{Introduction}

The novel coronavirus disease (COVID-19) is a new viral respiratory illness that was first identified on January 7, 2020 in Wuhan province, China. Symptoms associated with COVID-19 include high fever and shortness of breath. ${ }^{1}$ It is known that the disease is transmitted through droplets and direct contact. COVID-19 has been defined as a pandemic due to the global epidemic it has created. The new coronavirus belongs to a type of coronavirus family that can affect both animals and humans. A number of different viruses from the coronavirus family are responsible for causing severe respiratory diseases, such as Middle East respiratory syndrome (MERS) and severe acute respiratory syndrome (SARS)., ${ }^{2,3}$

The official name of the virus (severe acute respiratory syndrome-coronavirus 2 (SARS-CoV-2) was provided by the World Health Organization (WHO). The WHO uses the term COVID-19 to describe the disease caused by the virus. On January 30, 2020 COVID-19 was declared 
a global health emergency by the WHO. ${ }^{4}$ On March 11, 2020 the virus was declared a global epidemic. ${ }^{5}$

COVID-19 infections are characterized by high fever and coughing, and later by respiratory distress. In addition, it has been shown that additional symptoms, such as nausea and vomiting, diarrhea, myalgias, arthralgias, and anorexia, may occur. ${ }^{6,7}$ Studies have revealed that the virus is a member of the family of coronaviruses, which are single-strand RNA viruses. The virus is thought to be of animal origin because the first cases were linked to a large seafood and animal market in the region. It is known that the virus can pass from person-to-person through droplets and by direct contact. ${ }^{3,7}$ The virus is transmitted through contact with the eyes, mouth, and nasal mucosa after touching surfaces contacted by patients with respiratory secretions and by droplets emitted from coughing and sneezing. ${ }^{8,9}$

Dentists, dentistry students, and other healthcare staff are at risk of contracting infections during daily treatment procedures. ${ }^{10}$ Dental clinics are environments where disease transmission can occur easily. Aerosol transmission is also a possible route of transmission when there is an exposure to high concentrations of aerosols in a relatively closed environment. Routine dental procedures generate aerosols, which pose potential risks to the dentist, dental care staff, and patients. ${ }^{8}$ Those who are in close contact with patients with symptomatic and asymptomatic COVID-19, such as dentists and dental students in hospitals, are at even higher risk. ${ }^{2}$

Dentistry students are a high risk group for COVID-19 infection due to their inexperience, technical insufficiency, and lack of knowledge. Psychological states of dentistry students may be affected because of the high risk of contamination. We thus believe that the COVID-19 pandemic can cause high levels of anxiety in dentistry students. Dental procedures lead to an increased spread of risk for viruses from dental patients because dental practice involves face-to-face communication with patients and frequent exposure to saliva, blood, and other body fluids. COVID-19 is detected in the saliva of infected patients, thus dental, oral, and other healthcare professionals in particular should be very careful in protecting themselves against the spread of disease.,11 Also, the use of high speed hand pieces or ultrasonic instruments aerosolize patient secretions. The standard protective measures in daily clinical work are not sufficiently effective to prevent the spread of COVID-19. ${ }^{2}$

Therefore, the aim of the present study was to assess the levels of anxiety in students using the Health Anxiety Inventory (HAI), Beck Anxiety Inventory (BAI), State-Trait Anxiety Inventory I (STAI-I), and State-Trait Anxiety Inventory II (STAI-II), and to determine whether these variables are differentiated as a function of sex, dental school year, smoking habit, and lifestyle among a sample of dentistry students.

\section{Methodology}

\section{Study population}

A cross-sectional study was conducted at the Faculty of Dentistry at Firat University in March 2020, during the week after the first reported COVID-19 cases in Turkey. This study included a total of 355 students (190 females and 165 males) at the Faculty of Dentistry. First- and second-year dentistry students were evaluated preclinically, and third, fourth, and fifth year dentistry students were evaluated as clinical students. A total of 178 students worked in a preclinical setting and 177 students worked in the clinic. The total number of students at the Faculty of Dentistry was 363, but only 355 students completed all questionnaires. The response rate in this research was $97.7 \%$.

\section{Study design}

This cross-sectional study was approved by the Research Ethics Committee of Firat University (approval number: 2020/30-06). All participants were informed about this research verbally and in writing. All students volunteered to participate, and written informed consent was obtained from all of the participants prior to commencing the investigation. Then, the participants who agreed to participate in the study completed the questionnaires. The age, sex, and dental school year of each participant were recorded. HAI, BAI, STAI-I, and STAI-II were used to assess anxiety status. Participants with a history of mental illness, and students who had been prescribed anxiolytics, sedatives, or antidepressants were excluded. 


\section{Measures}

\section{Health Anxiety Inventory}

Salkovskis et al. ${ }^{12}$ developed the HAI to evaluate health anxiety. The Health Anxiety Scale is a self-reporting scale consisting of 18 items. Fourteen items of the scale consist of expressions containing four line answers that question the mental state of the patients. The remaining four questions focus on how the mental state might be affected assuming the students had acquired a serious illness. The scoring of the scale is between 0 and 3 for each item, and a high score indicates a high level of health anxiety. The Turkish adaptation, validity, and reliability were created by Aydemir et al. ${ }^{13}$ A reliability analysis of HAI revealed that the Cronbach's alpha internal consistency coefficient was $0.91 .^{13}$

\section{Beck Anxiety Inventory (BAI)}

The BAI is a self-evaluation scale that is used to determine the frequency of anxiety symptoms experienced by individuals. The BAI provides a Likert-type measurement (sum of degrees). There are four options in each of the 21 items. Each item is scored between 0 and 3. A high score obtained from the scale indicates severe anxiety. The Turkish adaptation, validity, and reliability of BAI were created by Mustafa et al. ${ }^{14}$ Based on the reliability analysis of the BAI, the Cronbach's alpha internal consistency coefficient was $0.93 .^{14}$

\section{Spielberger's Steady-State Anxiety Inventory}

(STAI-I and STAI -II)

STAI-I was developed by Spielberg et al. ${ }^{15}$ in 1973 to measure trait and state anxiety levels. STAI-I was developed to measure what is felt at that moment. STAI-II was developed to measure feelings experienced for the last 7 days. STAI-I and STAI-II consist of 20 items. The minimum score for both sections is 20 , and the maximum score is 80 . High scores indicate high anxiety levels, and low scores indicate low anxiety levels. ${ }^{15}$ The Turkish adaptation, validity, and reliability of STAI were created by Oner et al. ${ }^{16}$ Based on reliability analyses of STAI-I and STAI-II, the Cronbach's alpha internal consistency coefficients were 0.83 and 0.94 , respectively. ${ }^{16}$

\section{Statistical analysis}

SPSS 21.0 for Windows software was used to analyze data. The information was obtained from the students after all four scales were scored in accordance with the scoring directive. Qualitative data are expressed as numbers and percentages, while quantitative data are expressed as the mean \pm standard deviation $(S D)$. The compliance of the data with the normal distribution probability/hypothesis was analyzed using the Shapiro Wilk test. An independent Student's $t$-test was used to determine the difference between the two groups and a one-way ANOVA and Tukey HSD post hoc test was used for more than two groups. The Pearson's correlation coefficient was used to determine the relationship between the scales. The effect size (d) for $t$-test was 0.48 and the effect size (f) for one-way ANOVA was 0.20. Based on these analyses, the significance level was accepted as a $\mathrm{p}<0.05$. When power analysis was performed with a significance level of 0.05 at $90 \%$ power $(0.90)$ and an effect size of 0.1 , the number of participants was determined to be a minimum of 213 .

\section{Results}

This study involved a total of 355 students, of which 165 were males and 190 were females at the Faculty of Dentistry. The research study consisted of 178 preclinical students and 177 clinical students.

For males, the means \pm standard deviations (SDs) of the HAI, BAI, STAI-I, and STAI-I scores were $17.19 \pm 7.406,11.68 \pm 9.33,49.96 \pm 8.98$, and $45.42 \pm 8.299$, respectively. For females, the means \pm SDs of the HAI, BAI, STAI-I, and STAI-II scores were $19.17 \pm 6.77$, $16.68 \pm 11.362,50.27 \pm 9.350$, and $45.41 \pm 8.264$, respectively. There were significant sex differences between the HAI, BAI, STAI-I, and STAII scores. Specifically, female students had higher HAI and BAI scores than male students, and these differences were statistically significant $(\mathrm{p}=0.009$ and $\mathrm{p}=0.001$, respectively; Table 1 ).

For preclinical students, the means \pm SDs of the HAI, BAI, STAI-I, and STAI-II scores were $17.51 \pm 6.989$, $14.03 \pm 10.928,49.85 \pm 9.00$, and $45.12 \pm 7.762$, respectively. For clinical students, the mean \pm SD of the HAI, BAI, STAI-I, and STAI-II scores were $19.00 \pm 7.214$, 
$14.68 \pm 10.58,50.40 \pm 9.326$, and $45.71 \pm 8.762$, respectively. Statistically significant differences in HAI scores were detected between preclinical and clinical students $(\mathrm{p}=0.048$; Table 1$)$.

Of the students who participated in the study, $2.25 \%(\mathrm{n}=8)$ lived alone, $11.26 \%(\mathrm{n}=40)$ lived with friends, $78.59 \%(\mathrm{n}=279)$ lived with family, and $7.88 \%(n=28)$ lived with an extended family. There were statistically significant differences in STAI-I scores between students living with an extended family and those living without an extended family $(\mathrm{p}=0.039$; Table 1$)$.

No student had entered or exited a foreign country in the last 3 months. Forty-five students had been in close contact with people who had entered or exited a foreign country. For students who had close contact, the means \pm SDs of the HAI, BAI, STAI-I, and STAI-II scores were $20.22 \pm 6.99,16.64 \pm 9.69$, $50.09 \pm 10.43$, and $44.93 \pm 8.76$, respectively. For students who had noncontact, the means \pm SDs of the HAI, BAI, STAI-I, and STAI-II scores were $17.96 \pm 7.1$, $14.02 \pm 10.86,50.13 \pm 8.96$, and $45.48 \pm 8.20$, respectively. The HAI scores of students who had close contact were significantly higher than students who had no contact ( $p=0.047$; Table 1).

Sixty-four of the students participating in the study smoked cigarettes and 291 did not smoke cigarettes.
There were no statistically significant differences with respect to HAI, BAI, STAI-I, and STAI-II scores and smoking ( $p>0.05$ ). Table 2 shows the correlation between the scales; there was significant correlation between the four scales $(p<0.05)$.

\section{Discussion}

The result of the present study revealed that HAI scores were high in female dentistry students, clinical students, and students who had close contact with people who had entered and exited foreign countries. STAI-I scores were high in dentistry students who live with extended families.

Dental treatment environments are always open to risks of respiratory infections, such as by face-to-face interactions, frequent salivating, exposure to blood and other bodily fluids, and the use of sharp instruments. ${ }^{8}$ Health professionals who apply aerosol-producing procedures (e.g., dental procedures), dentists, and dentistry students, are defined as high risk groups. ${ }^{17,18}$ We believe that dentistry students with less education and experience are more susceptible to the risk of COVID-19 infection.

During dental procedures for patients with COVID-19 infections, the use of high speed hand pieces or ultrasonic instruments aerosolize their

Table 1. Relationship between different parameters and HAI, BAI, STAI-I, STAI-II level of students.

\begin{tabular}{lcccc}
\hline Variable & HAl & BAl & STAI-I & STAI-II \\
\hline Male & $17.19 \pm 7.40$ & $11.68 \pm 9.33$ & $49.96 \pm 8.95$ & $45.42 \pm 8.29$ \\
Female & $19.17 \pm 6.77$ & $16.68 \pm 11.36$ & $50.27 \pm 9.35$ & $45.41 \pm 8.26$ \\
p-value & $0.009^{*}$ & $0.001^{*}$ & 0.746 & 0.993 \\
Preclinic & $17.51 \pm 6.98$ & $14.03 \pm 10.92$ & $49.85 \pm 9.00$ & $45.12 \pm 8.76$ \\
Clinic & $19.00 \pm 7.21$ & $14.68 \pm 10.58$ & $50.40 \pm 9.32$ & $45.71 \pm 6.98$ \\
p-value & 0.573 & 0.574 & 0.508 & $0.048^{*}$ \\
Single & $18.25 \pm 7.16$ & $15.00 \pm 13.63$ & $51.38 \pm 9.73$ & $45.63 \pm 9.66$ \\
Friend & $18.75 \pm 7.88$ & $14.45 \pm 10.06$ & $50.08 \pm 9.57$ & $46.60 \pm 9.27$ \\
Family & $18.12 \pm 7.04$ & $14.34 \pm 10.87$ & $49.63 \pm 9.10^{\circ}$ & $45.19 \pm 8.14$ \\
Extended family & $18.86 \pm 7.16$ & $14.18 \pm 10.12$ & $54.82 \pm 7.91^{\circ}$ & $45.93 \pm 7.83$ \\
p-value & 0.921 & 0.998 & $0.039^{*}$ & 0.767 \\
Contact & $20.22 \pm 6.99$ & $16.64 \pm 9.69$ & $50.09 \pm 10.48$ & $44.93 \pm 8.76$ \\
Non-contact & $17.96 \pm 7.11$ & $14.02 \pm 10.86$ & $50.13 \pm 8.96$ & $45.48 \pm 8.20$ \\
p-value & $0.047^{*}$ & 0.126 & 0.677 & 0.976 \\
\hline
\end{tabular}

*Within the same measurement category, values with the same capital letter are statistically different by Tukey's post hoc analysis; Student's $\dagger$ test $p<0.05$. 
Table 2. The correlation between HAI, BAI, STAI-I, STAI-II level of students.

\begin{tabular}{lcc}
\hline Variable & $p$-value & $r$ \\
\hline HAI-BAI & 0.001 & $0.374^{*}$ \\
HAI-STAI-I & 0.001 & $0.282^{*}$ \\
HAI-STAI-II & 0.001 & 0.313 \\
BAI-STAI-I & 0.001 & 0.290 \\
BAI-STAI-II & 0.001 & $0.260^{*}$ \\
STAI-I-STAI-II & 0.001 & $0.499^{*}$ \\
\hline
\end{tabular}

${ }^{*}$ Correlation is significant at the 0.01 level.

secretions, saliva, or blood and can introduce COVID-19 to the surroundings. Due to the unique characteristics of dental procedures, in which a large number of droplets and aerosols are generated, the standard protective measures in daily clinical work are not sufficiently effective to prevent the spread of COVID-19, especially when patients are in the incubation period and are unaware that they are infected or choose to conceal their infection. ${ }^{2}$ In this study psychiatric conditions of dentistry students during the COVID-19 pandemic were evaluated because dentistry students are a high risk group for COVID-19 infections.

The results of this study revealed a significant correlation between psychiatric scales (HAI, BAI, STAI-I, and STAI-II) during the COVID-19 pandemic in dentistry students. According to this study, HAI and BAI scores were more common in females than males, and females had higher levels of Health and Beck anxiety scores $(p=0.009$ and $p=0.001$, respectively). Physiological sensations related to stress, depression, fear, social phobia, and panic are widespread in females, which may be related to anxiety. ${ }^{19}$ According to this data, it can be concluded that females are affected by more negative sensational status than males and the anxiety is positively related to psychological status. Huri et al. ${ }^{20}$ conducted a study on dentists and reported that the value of depression was significantly higher in female physicians. In studies related to depression epidemiology, the common belief is that the frequency and prevalence of depression was higher in females than males..$^{21,22}$ These results may be related to biological factors (hormonal changes, such as menstrual period), social factors (patriarchal ideology and economic status), and cultural factors (excessive workload at home and work). Indeed, these factors may affect the psychological state of females. ${ }^{23,24}$

Clinical students had higher Health anxiety scores than preclinical students $(p=0.48)$. This result can be explained by the fact that clinical students are in contact with patients for extended periods during dental treatment. Furthermore, the risk of infection to clinical students is higher than preclinical students. Clinical students had increased patient contact during their education and clinical years. They are at high risk of cross-infection. ${ }^{25}$ The risk of COVID-19 transmission has led to an increase in HAI among clinical students.

HAI scores for students who had close contact with people with foreign country entry and exit histories were higher than students without such a history $(p=0.48)$. Because COVID-19 first occurred in Wuhan and spread worldwide, people from abroad are more likely to become infected with COVID-19. The first case in our country was confirmed in a person who had close contact with people who had foreign country entry. After the first case, another important factor leading to the rapid increase in COVID-19 was individuals who had returned from performing religious duties in Saudi Arabia. Persons who are in contact with individuals who have been abroad are a high risk group due to COVID-19. Accordingly, students who are in contact with individuals who had a foreign country entry and exit history have high HAI scores.

Individuals living together (friends, family, and extended family) with students did not have statistically significant differences with respect to HAI, BAI, and STAI-II ( $p>0.05)$. There was a significant difference in STAI-I between students who live with an extended family and students who did not live with an extended family $(p=0.039)$. As with all healthcare professionals, dentistry students are concerned about infecting family members with COVID-19. Due to the characteristics of dental clinics, there may be a high risk of cross-infection between patients and dentistry students and their families. Current observations 
suggested that people of all ages are generally susceptible to this new infectious disease. This risk is high in the elderly and individuals with chronic infectious diseases. For these reasons, dentistry students have legitimate concerns of infecting their extended families.

The limitation of this study was that dental student anxiety was evaluated 1 week after the first COVID-19 case was diagnosed in Turkey (without interruption of hospital and education). During the COVID-19 pandemic, dental student anxiety was evaluated again, thus the psychological state during and after the COVID-19 pandemic was compared.

\section{Conclusion}

During the COVID-19 pandemic, HAI and BAI scores were higher in female dentistry students. Clinical dentistry students had higher HAI scores than preclinical students. Students who had close contact with people who had entered and exited a foreign country had high HAI scores. Dentistry students who live with extended families had higher STAI-I scores than other students.

\section{Acknowledgements}

The authors thank all participants for their invaluable contribution to this research.

\section{References}

1. Sohrabi C, Alsafi Z, O’Neill N, Khan M, Kerwan A, Al-Jabir A, et al. World Health Organization declares global emergency: a review of the 2019 novel coronavirus (COVID-19). Int J Surg. 2020 Apr;76:71-6. https://doi.org/10.1016/j.ijsu.2020.02.034

2. Meng L, Hua F, Bian Z. Coronavirus Disease 2019 (COVID-19): emerging and future challenges for dental and oral medicine. J Dent Res. 2020 May;99(5):481-7. https://doi.org/10.1177/0022034520914246

3. Peng X, Xu X, Li Y, Cheng L, Zhou X, Ren B. Transmission routes of 2019-nCoV and controls in dental practice. Int J Oral Sci. 2020 Mar;12(1):9. https://doi.org/10.1038/s41368-020-0075-9

4. Mahase E. China coronavirus: WHO declares international emergency as death toll exceeds 200. BMJ. 2020 Jan;368:m408. https://doi.org/10.1136/bmi.m408

5. Neher RA, Dyrdak R, Druelle V, Hodcroft EB, Albert J. Potential impact of seasonal forcing on a SARS-CoV-2 pandemic. Swiss Med Wkly. 2020 Mar;150:w20224. https://doi.org/10.4414/smw.2020.20224

6. Wang D, Hu B, Hu C, Zhu F, Liu X, Zhang J, et al. Clinical characteristics of 138 hospitalized patients with 2019 novel coronavirus-infected pneumonia in Wuhan, China. JAMA. 2020 Mar;323(11):1061-9. https://doi.org/10.1001/jama.2020.1585

7. Xu H, Zhong L, Deng J, Peng J, Dan H, Zeng X, et al. High expression of ACE2 receptor of 2019-nCoV on the epithelial cells of oral mucosa. Int J Oral Sci. 2020 Feb;12(1):8. https://doi.org/10.1038/s41368-020-0074-x

8. Ge ZY, Yang LM, Xia JJ, Fu XH, Zhang YZ. Possible aerosol transmission of COVID-19 and special precautions in dentistry. J Zhejiang Univ Sci B. 2020 May;21(5):361-8. https://doi.org/10.1631/jzus.B2010010

9. Sabino-Silva R, Jardim AC, Siqueira WL. Coronavirus COVID-19 impacts to dentistry and potential salivary diagnosis. Clin Oral Investig. 2020 Apr;24(4):1619-21. https://doi.org/10.1007/s00784-020-03248-x

10. Yildirim TT, Acun Kaya F, Kaya CA. Assessment of Hepatitis B vaccination status of students of faculty of dentistry. Int Dent Res. 2017;7(3):46-53. https://doi.org/10.5577/intdentres.2017.vol7.no3.1.

11. To KK, Tsang OT, Yip CC, Chan KH, Wu TC, Chan JM, et al. Consistent detection of 2019 novel coronavirus in saliva. Clin Infect Dis. $2020 \mathrm{Jul} ; 71$ (15):841-3. https://doi.org/10.1093/cid/ciaal49

12. Salkovskis PM, Rimes KA, Warwick HM, Clark DM. The Health Anxiety Inventory: development and validation of scales for the measurement of health anxiety and hypochondriasis. Psychol Med. 2002 Jul;32(5):843-53. https://doi.org/10.1017/S0033291702005822

13. Aydemir Ö, Kirpinar I, Sati T, Uykur B, Cengisiz C. Reliability and validity of the Turkish version of the health anxiety inventory. Noro Psikiyatr Ars. 2013;50(4):325-31. Turkish. https://doi.org/10.4274/npa.y6383

14. Mustafa U, Sahin Nesrin H, Husnu E. Turkish version of the Beck Anxiety Inventory: psychometric properties, 1998. J Cogn Psychother. 1998;12:163-72.

15. Spielberger C, Gorsuch R, Lushene R. STAI manual for the State-Trait Anxiety Inventory. Palo Alto: Calif. Consulting Psychologists Press; 1983.

16. Öner N, Le Compte A. Durumluk - Sürekli Kaygı Envanter El Kitabı. İstanbul: Boğaziçi Üniversitesi Yayınları; 1985. 
17. Adams JG, Walls RM. Supporting the health care workforce during the COVID-19 global epidemic. JAMA. 2020 Apr;323(15):1439-40. https://doi.org/10.1001/jama.2020.3972

18. Kampf G, Todt D, Pfaender S, Steinmann E. Persistence of coronaviruses on inanimate surfaces and their inactivation with biocidal agents. J Hosp Infect. 2020 Mar;104(3):246-51. https://doi.org/10.1016/i.jhin.2020.01.022

19. Talo Yildirim T, Dundar S, Bozoglan A, Karaman T, Dildes N, Acun Kaya F, et al. Is there a relation between dental anxiety, fear and general psychological status? PeerJ. 2017 Feb;5:e2978. https://doi.org/10.7717/peeri.2978

20. Huri M, Bağış N, Eren H, Umaroğlu M, Orhan K. Association between burnout and depressive symptoms among Turkish dentists. J Dent Sci. 2016 Dec;11(4):353-9. https://doi.org/10.1016/i.jds.2016.03.006

21. Ackard DM, Neumark-Sztainer D, Story M, Perry C. Parent-child connectedness and behavioral and emotional health among adolescents. Am J Prev Med. 2006 Jan;30(1):59-66. https://doi.org/10.1016/j.amepre.2005.09.013

22. Adewuya AO, Ola BA, Aloba OO, Mapayi BM, Oginni OO. Depression amongst Nigerian university students: prevalence and sociodemographic correlates. Soc Psychiatry Psychiatr Epidemiol. 2006 Aug;41(8):674-8. https://doi.org/10.1007/s00127-006-0068-9

23. Stubbs C, Mattingly L, Crawford SA, Wickersham EA, Brockhaus JL, McCarthy LH. Do SSRIs and SNRIs reduce the frequency and/or severity of hot flashes in menopausal women. J Okla State Med Assoc. 2017 May;110(5):272-4.

24. Blane D. Social determinants of health: socioeconomic status, social class, and ethnicity. Am J Public Health. 1995 Jul;85(7):903-5. https://doi.org/10.2105/AJPH.85.7.903

25. Binalrimal S, AIDrees A, AIWehaibi M, AlAsmary M, AIShammery A, AlHaidri E, et al. Awareness and compliance of dental students and interns toward infection control at Riyadh Elm University. GMS Hyg Infect Control. 2019 Aug;14(14):Doc10. https://doi.org/10.3205/dgkh000326 